American Journal of BioScience
2021; $9(2):$ : $63-71$
http://www.sciencepublishinggroup.com/j/ajbio
doi: 10.11648 /j.ajbio.20210902.15
ISSN: $2330-0159$ (Print); ISSN: $2330-0167$ (Online)

\title{
Genotype $\times$ Environment Interaction and Selection of High Yielding Wheat Genotypes for Different Wheat-growing Areas of Ethiopia
}

\author{
Gadisa Alemu ${ }^{1,}$, , Alemu Dabi ${ }^{1}$, Nagesh Geleta ${ }^{1}$, Ruth Duga ${ }^{1}$, Tafesse Solomon ${ }^{1}$, \\ Habtemariam Zegaye ${ }^{1}$, Abebe Getamesay ${ }^{1}$, Abebe Delesa ${ }^{1}$, Dawit Asnake ${ }^{1}$, Bayisa Asefa ${ }^{1}$, \\ Yewubdar Shewaye ${ }^{2}$, Bekele Geleta Abeyo ${ }^{3}$, Ayele Badebo ${ }^{3}$ \\ ${ }^{1}$ Ethiopian Institute of Agricultural Research, Kulumsa Agricultural Research Center, Asella, Ethiopia \\ ${ }^{2}$ Dabra Zeit Agricultural Research Center, Bishoftu, Ethiopia \\ ${ }^{3}$ CIMMYT, Addis Ababa, Ethiopia
}

Email address:

gadalemu@gmail.com (G. Alemu)

${ }^{*}$ Corresponding author

To cite this article:

Gadisa Alemu, Alemu Dabi, Nagesh Geleta, Ruth Duga, Tafesse Solomon, Habtemariam Zegaye, Abebe Getamesay, Abebe Delesa, Dawit Asnake, Bayisa Asefa, Yewubdar Shewaye, Bekele Geleta Abeyo, Ayele Badebo. Genotype $\times$ Environment Interaction and Selection of High Yielding Wheat Genotypes for Different Wheat-growing Areas of Ethiopia. American Journal of BioScience. Vol. 9, No. 2, 2021 , pp. 63-71. doi: 10.11648/j.ajbio.20210902.15

Received: February 9, 2021; Accepted: March 24, 2021; Published: April 23, 2021

\begin{abstract}
Evaluation of wheat genotypes under different environments is essential for testing stability of their performance and range of adaptations. Where, enhanced grain yield has been achieved in bread wheat (Tritium aestivum L.) through the development of adaptable, high-yielding, and rust-resistant genotypes by evaluating advanced genotypes for yield in multienvironment trials. The adaptability of a genotype over diverse environments is usually tested by the degree of its interaction with different environments under which it is grown. This study examines fifteen bread wheat genotypes for two consecutive years (2016 and 2017) across eight locations in Ethiopia. The experiment was laid out using a Randomized Complete Block design and replicated three times intending to determine high-yielding advanced genotype and release best performing genotypes as a variety for the end-user. Highly significant $(\mathrm{P} \leq 0.001)$ effects of genotype, environment, and genotype by environment interaction were observed for grain yield. The AMMI analysis of variance indicated that environments accounted for $52.34 \%$ of the total sum of squares for grain yield (genotype yields ranged from $5.76 \mathrm{t} / \mathrm{ha}$ at E-11 to $1.31 \mathrm{t} / \mathrm{ha}$ at E-7). followed by interaction (22.95\%) and genotypes (11.31\%).The genotype ETBW8260 (G4) exhibited high mean grain yield and well performed to the tested environments. The ETBW8260 (G4) was selected as early maturing, high yielding, resistant to yellow rust and fitting for low to midland wheat growing areas and has a yield advantage over the standard Ogolcho and the local Kakaba. Both locations and genotypes are dispersed widely in all quadrants in the AMMI-1 biplot. As per the YSI Ogolcho (\#15) ETBW8303 (G2), ETBW8454 (G12), ETBW8261 (G5), ETBW8406 (G10), ETBW8310 (G3), and ETBW8260 (G4), the genotypes of bread wheat were stable. Besides, the genotype ETBW8260 (G4 has highest mean yield with good stability. Therefore, after a one-year variety verification trial, ETBW8260 is released as a commercial variety in 2019 and a designated local name called "Balcha" and recommended for low-medium part of wheat production agroecology of the country.
\end{abstract}

Keywords: AMMI, Environment, Yield, Variety

\section{Introduction}

In Ethiopia, there are diverse agro-ecology and climatic conditions which are suitable for the production of various cereal crops. So, having a different range of altitudes, soils and climatic conditions provide ecological settings suitable for the cultivation of diverse species of wheat [1]. Bread wheat in Ethiopia is an important cereal crops in terms of 
production and consumption. As reported by [2] wheat is produced in most highlands of the northern, central, and south-eastern parts of Ethiopia. This means that it can be produced in almost all regions of the country including pastoral and agro-pastoral areas like Afar, Gambela, and Somali regions. However, the majority $(85 \%)$ of production of wheat is grown in Oromia and Amhara regions of Ethiopia [3].

Wheat has many uses like that of other cereal crops produced in the country. In Ethiopia, wheat grain is used in the preparation of different traditional as well as modern processed food products such as injera and other industrial processed products like pasta and [4]. Besides, wheat straw is commonly used as a roof tacking material and as a feed for animals. On average, wheat production, area coverage and its productivity have shown increasing rate specifically from 2005 to 2017 in Ethiopia. Annually it grown in 1.7 million hectares of land which is $13.38 \%$ of the total area of land used for cereal production [5]. It ranks second after maize contributing $15.17 \%$ of the total annual cereal production.

Genotype $\mathrm{x}$ environment interactions are of major importance, because they provide information about the effect of different environments on cultivar performance and have a key role for assessment of performance stability of the breeding materials [6]. The presence of the GEI indicates that the phenotypic expression of one genotype might be superior to another genotype in one environment but inferior in a different environment and the existence of a significant GEI complicates the interpretation of the results. Stable genotypes have the same reactions over the environments. Yield potential of a genotype is the result of its performance over locations and years. Therefore, stability analysis of genotypes is required in the presence of GEI to ascertain high yielding and relatively stable genotypes. For several test environments, the GEI governs the credentials of the most stable genotypes that are suitable for specific environment [7]. Thus, the genotypes possessing genetic homeostasis are essential to increase average yield.

The adaptability of a variety over a diverse environment is usually tested by the degree of its interaction with different environments under which it is planted [8]. This could be performed by exposing the varieties to different soil types, soil fertility, moisture levels, environments and cultural practices at farmers' fields in order to evaluate the performance and stability of the varieties across the various testing locations. Assessing grain yield of a set of cultivars in a multi-environmental trial, changes are commonly observed in the relative performance of genotypes with respect to each other across locations. This could enable the breeders to select superior genotypes for the target environment. In order to identify superior genotypes across multiple environments, plant breeders conduct trials across locations and years, especially during the final stages of cultivar development. Several studies of genotype by environment interactions and yield stability have been reported on wheat grown under different locations and conditions of Ethiopia [9, 10, and 11].

Wheat production can increased up through genotype having broader genetic base and better performance under various agro-climatic conditions. Improvement gets complicated when a trait is environment-driven and selection gets more complex [12]. The success of wheat improvement activities largely depends on the identification of superior genotypes for cultivation by assessing stability in performance of genotypes with respect to changes across environment and performance with respect to changing environmental factors over time with a given environment. The performance of a variety is the resultant effect of its genotype and the environment in which the genotypes are tested. The process of variety development of wheat genotypes for disease resistance, wide adaptability and high yield, which resulted in the release of many cultivars to end user in the country, is continuing year after year through various research institutes and universities. However, most of these cultivars were out of production due to their susceptibility to rust disease. By conducting various breeding research, different bread wheat varieties were developed to alleviate the wheat production constraints, in Ethiopia. Developing new improved variety by identification of adaptable, high-yielding and rust-resistant genotypes through the evaluation of advanced wheat genotypes for yield in multi-environment trials would form a basis for breeding. Therefore, this study aimed to determine high-yielding advanced bread wheat genotypes and release best performing genotypes across different wheat growing areas of Ethiopia as a variety for the end user.

\section{Materials and Methods}

\subsection{Location Descriptions}

The genotypes were evaluated in twelve locations (year by location) in 2016 and 2017 main cropping seasons in the low to midland of Ethiopia.

Table 1. List of test locations and their descriptions.

\begin{tabular}{|c|c|c|c|c|c|c|}
\hline \multirow{2}{*}{ Location } & \multicolumn{2}{|c|}{ Geographic position } & \multirow{2}{*}{ Altitude } & \multicolumn{2}{|c|}{ Temperature $\left({ }^{\circ} \mathrm{C}\right)$} & \multirow{2}{*}{ Rainfall (mm) } \\
\hline & Latitude & Longitude & & Min & Max & \\
\hline Kulumsa & $08^{\circ} 01^{\prime} 10^{\prime \prime} \mathrm{N}$ & $39^{\circ} 09^{\prime} 11^{\prime \prime} \mathrm{E}$ & 2200 & 10.5 & 22.8 & 820 \\
\hline Asasa & $07^{\circ} 07^{\prime} 09^{\prime \prime} \mathrm{N}$ & $39^{\circ} 11^{\prime} 50^{\prime \prime} \mathrm{E}$ & 2340 & 5.8 & 24 & 620 \\
\hline Dhera & $08^{\circ} 19^{\prime} 10^{\prime \prime} \mathrm{N}$ & $39^{\circ} 19^{\prime} 13^{\prime \prime} \mathrm{E}$ & 1650 & 14 & 27.8 & 680 \\
\hline Melkasa & $08^{\circ} 24^{\prime} \mathrm{N}$ & $39^{\circ} 12^{\prime} \mathrm{E}$ & 1550 & 13.6 & 28.6 & 763 \\
\hline A. Tena & $08^{\circ} 30 \mathrm{~N}$ & $38^{\circ} 95 \mathrm{E}$ & 1611 & NA & NA & 728 \\
\hline A. Nagele & $7^{\circ} 21^{\prime} \mathrm{N}$ & $38^{\circ} 42^{\prime} \mathrm{E}$ & 2043 & 10 & 25 & 750 \\
\hline Halaba & $7.4933^{\circ} \mathrm{N}$ & $38.1900^{\circ} \mathrm{E}$ & 1726 & 17.6 & 22.5 & 900 \\
\hline Haramaya Un. & $9.4083^{\circ} \mathrm{N}$ & $42.0345^{\circ} \mathrm{E}$ & 2047 & 9.9 & 24.18 & 800.9 \\
\hline
\end{tabular}




\subsection{Experimental Materials}

Thirteen advanced bread wheat genotypes including two bread wheat varieties for the check released by National
Bread Wheat Research Coordinating Center based at Kulumsa Agricultural Research Center (KARC) were evaluated in this study.

Table 2. List of materials tested in the experiment in 2016 and 2017 cropping season.

\begin{tabular}{lll}
\hline Code & Genotype & Pedigree \\
\hline G1 & Ogolcho & WORRAKATTA/2*PASTOR \\
G2 & ETBW8303 & FRET2/KUKUNA//FRET2/3/FRNCLN \\
G3 & ETBW8310 & ND643/2*WBLL1//ATTILA*2/PBW65/3/MUNAL \\
G4 & ETBW8260 & CROC_1/AE.SQUARROSA (213)//PGO/10/ATTILA*2/9/KT/BAGE//FN/U/3/BZA/4/TRM/5/ALDAN/6/SERI/7/VEE\#10/8/OPATA \\
G5 & ETBW8261 & CHRZ//BOW/CROW/3/WBLL1/4/CROC_1/AE.SQUARROSA (213)//PGO \\
G6 & ETBW8076 & Line 1 Singh/(Cham6/WW1402) \\
G7 & ETBW8085 & Line 3 Singh/(Cham6/WW1402) \\
G8 & ETBW8289 & MUTUS*2/TECUE \#1 \\
G9 & ETBW8348 & CMH82A.1294/2*KAUZ//MUNIA/CHTO/3/MILAN/4/AMIR-2 \\
G10 & ETBW8406 & TILILA/MUBASHIIR-1 \\
G11 & ETBW8437 & P1.861/RDWG//PBW343/3/MUNIA/ALTAR 84//AMSEL \\
G12 & ETBW8454 & CHAM-4/SHUHA'S'6/2*SAKER/5/RBS/ANZA/3/KVZ/HYS//YMH/TOB/4/BOW'S" \\
G13 & ETBW8387 & SERI.1B//KAUZ/HEVO/3/AMAD/4/PFAU/MILAN \\
G14 & ETBW8394 & SERI.1B//KAUZ/HEVO/3/AMAD/4/PFAU/MILAN \\
G15 & Kakaba & KIRITATI/SERI/RAYO \\
\hline
\end{tabular}

\subsection{Experimental Layout}

The trial was conducted in a randomized complete block design with four replications at all environments. The experimental plot for each entry consisted of six rows of 2.5 meter length and rows were spaced at $20 \mathrm{~cm}$ apart. Spacing between plots and replications were $1 \mathrm{~m}$ and $1.5 \mathrm{~m}$, respectively. The seed rate was $150 \mathrm{~kg} / \mathrm{ha}$. Planting was done following the onset of rain and recommendations of the respective locations. The trial was conducted with application of $100 \mathrm{~kg} / \mathrm{ha}$ of DAP and $100 \mathrm{~kg} / \mathrm{ha}$ of urea fertilizers at each location. All DAP was applied at planting while urea was applied in split: half at the time of planting and the remaining half at tillering stage. In addition, other relevant field trial management practices were carried out uniformly for all experimental units. Data were taken for days to $50 \%$ heading, plant height, days to $90 \%$ maturity, and hectoliter weight, thousand kernel weight and grain yield.

\subsection{Statistical Analysis}

Data were subjected to analysis of variance (ANOVA) for each environment separately; and also combined analysis of variance was conducted to determine the effect of environment (E), genotype (G) and GE interaction on the expression of traits. The SAS software version 9.3 and Rsoftware were used for combined ANOVA and AMMI analysis.

\subsection{Stability Analysis}

The stability analysis among genotypes over environments was done using AMMI analysis multivariate analysis methods as described below.

AMMI analysis

The AMMI model combines the analysis of variance for the main effects of $\mathrm{G}$ and $\mathrm{E}$ with principal components analysis of GEI. AMMI-2 biplot was constructed in the dimension of the first two IPCA, using a singular value decomposition procedure [13]. The AMMI analysis was performed using the model suggested by [14] as:

$$
Y_{i j}=\mu+G_{i}+E_{j}+\sum_{n=1}^{n} \lambda_{n} \alpha_{i n} y_{j n}+e_{i j k}
$$

Where $Y_{i j}$ is the yield of the $i^{\text {th }}$ genotype in the $j^{\text {th }}$ environment, $\mu$ is the grand mean, $G_{i}$ is the mean of the $i^{\text {th }}$ genotype minus the grand mean, $E_{j}$ is the mean of the $j^{\text {th }}$ environment minus the grand mean, $\lambda_{n}$ is the square root of the Eigenvalue of the principal component analysis (PCA) axis, $\alpha_{i n}$ and $y_{j n}$ are the principal component scores for PCA axis $n$ of the $\mathrm{i}^{\text {th }}$ genotype and $\mathrm{j}^{\text {th }}$ environment and $\mathrm{e}_{\mathrm{ijk}}$ is the error term.

AMMI stability value (ASV): ASV, as described by [15] was calculated as follows:

$$
\mathrm{ASV}=\sqrt{\left[\frac{\mathrm{IPCA}_{\text {sum of square }}}{\mathrm{IPCA}_{\text {sum of square }}}\left(\mathrm{IPCA} 1_{\text {Score }}\right)\right]^{2}+\left(\mathrm{IPCA} 2_{\text {Score }}\right)^{2}}
$$

Where, $\frac{\text { IPCA } 1_{\text {sum }} \text { of square }}{{ }_{\text {PCA }} \text { sum of square }}$ is the weight given to the IPCA1value by dividing the IPCA 1 sum of squares by the IPCA 2 sum of squares.

Yield stability index: The yield stability index (YSI) was calculated as: $\mathrm{YSI}=\mathrm{RASV}+\mathrm{RY}$

Where, RASV is the rank of the AMMI stability value and $\mathrm{RY}$ is the rank of the mean grain yield of genotypes (RY) across environments.

\section{Result and Discussion}

The combined analysis of variance revealed significant $(\mathrm{P}<0.001)$ effects for all sources of variation (environment, genotype, and interaction) for grain yield (Table 3). Environment and genotype accounted for about 52.34\% and $11.31 \%$ of the total variation for grain yield, respectively, 
while the GE interaction explained $22.95 \%$ of the total variation (Table 3 ). This high percentage of the sum of squares attached to the environment is an indication that the test environments were very diverse and play a significant role in influencing yield performance and causing most of the variation in grain yield. The result was in agreement with the findings of [11 and 16] who reported that bread wheat grain yield was significantly affected by the environment. [10 and 17] also reported that bread wheat grain yield was significantly affected by the environment. Genotypes revealed highly significant $(\mathrm{p}<0.001)$ differences for grain yield. This indicates that there was a genetic difference among genotypes for this trait. This agrees with the finding of [17] who reported that genotypes were highly significantly different for grain yield. Similarly, [11] reported that the bread wheat genotypes had a wider genetic variability for the entire traits.

The GEI effect $(22.95 \%$ of the total sum of squares) was two times higher than the genotypic effect. This may indicate the existence of a considerable amount of differential response among the genotypes to changes in various environments and the differential discriminating ability of the test environments. This agreed with the report of [18] the
GEI effect was higher than the genotypic effect. In general, from the combined analyses of variance (Table 3 ) superiority of genotypes across environments could not be identified by considering their mean grain yield performance because GEI was highly significant. The magnitude of GEI caused more dissimilarity in genetic systems that are controlling physiological processes that are conferring yield stability in different environments. It was possible to proceed and apply statistical stability methods to analyze GEI for the identification of the most stable genotypes in different environments and to select specific genotypes for specific environments. [19] elaborated a significant genotype by environment interaction for grain yield can reduce the usefulness of subsequent analyses, restrict the significance of inferences that would otherwise be valid, and seriously limit the feasibility of selecting superior genotypes, and thus seriously limit efforts to improved variety development. [14] magnified the relevance of qualitative or crossover interactions in agriculture and appropriate statistical analyses are required for quantifying them. Thus, it is very important to study in-depth the yield levels, adaptation patterns, and stability of bread wheat genotypes in multi-environments.

Table 3. AMMI analysis of variance for grain yield of 15 bread wheat genotypes.

\begin{tabular}{|c|c|c|c|c|}
\hline Source of variation & Df & Sum Square & Explained & Mean square \\
\hline ENV & 11 & 1105.7 & 52.34 & $100.518^{* * *}$ \\
\hline REP (ENV) & 36 & 57.93 & 2.74 & $1.609^{* * *}$ \\
\hline GEN & 14 & 238.98 & 11.31 & $17.07^{* * *}$ \\
\hline ENV:GEN & 154 & 484.88 & 22.95 & $3.149^{* * *}$ \\
\hline $\mathrm{PC} 1$ & 24 & 357.21 & 73.7 & $14.88^{* * *}$ \\
\hline PC2 & 22 & 40.06 & 8.3 & $1.82^{* * *}$ \\
\hline PC3 & 20 & 38.36 & 7.9 & $1.92^{* * *}$ \\
\hline PC5 & 16 & 13.67 & 2.8 & $0.85^{*}$ \\
\hline PC6 & 14 & 5.04 & 1.0 & 0.36 \\
\hline PC7 & 12 & 3.91 & 0.8 & 0.33 \\
\hline PC8 & 10 & 3.35 & 0.7 & 0.33 \\
\hline PC9 & 8 & 2.11 & 0.4 & 0.26 \\
\hline PC10 & 6 & 0.57 & 0.1 & 0.09 \\
\hline Residuals & 504 & 228.02 & 10.79 & 0.452 \\
\hline
\end{tabular}

Where; ${ }^{* * *}$ significantly difference at $\mathrm{P}<0.001$

\section{Mean yield performance across testing locations}

Promising genotypes need to be evaluated in a multienvironmental test over several years for the identification of the stable and widely adapted genotypes as a result, a significant GEI may be either crossover, in which a significant change in rank occurs from one environment to others, or a non-crossover GEI, in which the ranking of genotypes remains constant across environments and the interaction was significant because of change in the magnitude of response. The mean grain yield was observed from 13 bread wheat genotypes with 2 checks across eight environments and ranged from 2.02 to $4.18 \mathrm{t} / \mathrm{ha}$ and the highest grain yield was obtained from genotypes ETBW8260 (G4) and ETBW8261 (G5), while the lowest grain yield was obtained from genotype ETBW8085 (G7). The grain yield ( $t /$ ha) data of the bread wheat genotype at different locations is shown in Table 4. The highest mean grain yield was obtained at Kulumsa 2017 (E-11) (5.76 t/ ha) followed by Dhera 2016 (E-2) (4.76 t/ha) and the lowest at Dhera in 2017 (E-9) $(1.31 \mathrm{t} / \mathrm{ha})$. The difference in grain yield is due to favorable and unfavorable environmental conditions. The grain yield of genotypes was highest at Asasa in the 2016 cropping season, and at Kulumsa in the 2017 cropping season. Thus, the variations among the testing environments showed the existence of considerable variability for wheat production in the moisture stress areas and optimum moisture areas of the country. Moreover, the presence of interaction effect would imply inconsistent response of genotypes across the test environments. The significant genotypes $\mathrm{x}$ environment interaction could be due to rank changes of the genotypes across the environment in the differences between the genotypes over the environment. The significant effects of GE interaction indicated that, the presence of substantial differences in the relative performance of genotypes at 
different locations. Nevertheless, due to strong crossover type of interaction, the grain yield of wheat genotypes varied from $0.64 \mathrm{t} / \mathrm{ha}$ in genotype ETBW8085 (G7) grown at Alem Tena in 2016 to 7.28 t/ha of ETBW8261 (G5) grown at Kulumsa in 2017 cropping season (Table 4). This rank change would be the source of the significant crossover GEI revealed in this data set. However, the selection of best lines both for specific and wide adaptation based on the mean results would be misleading [13] Six advanced bread wheat genotypes were showed the best yield performances than the released variety Ogolcho and nine advanced genotypes were high yielder than the released variety Kakaba (Table 4). The genotype ETBW8260 was the most promising genotype giving the highest yield in environment 1 (Kulumsa 2016) (6.36 t/ha) and environment 3 (Asasa 2016) (7.09 t/ha) and overall mean basis $(4.18 \mathrm{t} / \mathrm{ha})$.

Table 4. The mean grain yield of 15 bread wheat genotypes tested in two years across twelve locations (year by locations) (2016-2017).

\begin{tabular}{|c|c|c|c|c|c|c|c|c|c|c|c|c|c|c|}
\hline Code & Genotype & E-1 & E-2 & E-3 & E-4 & E-5 & E-6 & E-7 & E-8 & E-9 & E-10 & E-11 & E-12 & Mean \\
\hline G1 & Ogolcho & 5.05 & 3.01 & 5.72 & 2.68 & 1.80 & 1.38 & 2.37 & 3.13 & 3.34 & 4.89 & 5.77 & 3.91 & 3.59 \\
\hline G2 & ETBW8303 & 3.69 & 2.33 & 3.85 & 3.16 & 2.30 & 1.64 & 2.15 & 3.41 & 3.32 & 4.62 & 6.05 & 4.48 & 3.42 \\
\hline G3 & ETBW8310 & 3.62 & 2.10 & 4.62 & 3.20 & 2.00 & 1.57 & 2.22 & 2.98 & 3.73 & 6.44 & 7.59 & 3.72 & 3.65 \\
\hline G4 & ETBW8260 & 6.36 & 3.11 & 7.09 & 2.71 & 2.20 & 1.48 & 1.70 & 3.61 & 3.90 & 6.63 & 7.19 & 4.27 & 4.18 \\
\hline G5 & ETBW8261 & 5.11 & 2.89 & 5.11 & 3.27 & 2.00 & 1.52 & 2.69 & 3.07 & 2.99 & 6.73 & 7.28 & 3.86 & 3.88 \\
\hline G6 & ETBW8076 & 1.87 & 2.65 & 1.67 & 2.15 & 2.00 & 1.70 & 1.75 & 4.06 & 2.80 & 1.13 & 2.78 & 2.89 & 2.29 \\
\hline G7 & ETBW8085 & 1.53 & 2.30 & 1.87 & 1.56 & 2.10 & 0.64 & 1.74 & 1.34 & 3.54 & 0.86 & 2.25 & 4.45 & 2.02 \\
\hline G9 & ETBW8348 & 4.12 & 2.74 & 3.59 & 3.47 & 1.50 & 1.38 & 1.51 & 2.90 & 2.86 & 3.41 & 5.84 & 3.64 & 3.08 \\
\hline G10 & ETBW8406 & 5.51 & 3.25 & 5.38 & 2.71 & 2.10 & 0.95 & 1.94 & 2.38 & 4.09 & 6.22 & 7.02 & 4.41 & 3.83 \\
\hline G11 & ETBW8437 & 5.16 & 2.65 & 4.98 & 3.7 & 1.80 & 1.13 & 2.28 & 2.05 & 2.75 & 6.21 & 7.23 & 4.22 & 3.68 \\
\hline G12 & ETBW8454 & 4.46 & 3.89 & 5.22 & 3.24 & 1.90 & 1.37 & 2.11 & 3.18 & 2.49 & 6.20 & 6.48 & 4.34 & 3.74 \\
\hline G13 & ETBW8387 & 3.99 & 2.38 & 4.43 & 2.48 & 2.20 & 1.23 & 1.81 & 2.21 & 2.94 & 6.25 & 5.90 & 4.45 & 3.35 \\
\hline G14 & ETBW8394 & 4.24 & 2.24 & 4.94 & 2.56 & 1.90 & 1.23 & 1.96 & 1.85 & 3.71 & 6.57 & 6.14 & 4.14 & 3.45 \\
\hline G15 & Kakaba & 3.89 & 3.14 & 3.18 & 3.13 & 2.20 & 1.10 & 2.38 & 2.66 & 2.64 & 3.72 & 5.52 & 4.21 & 3.14 \\
\hline
\end{tabular}

Where E-1: Kulumsa 2016, E-2: Dhera 2016, E-3: Asasa 2016, E-4: Melkasa 2016, E-5: Arsi Nagele 2016, E-6: Alem Tena 2016, E-7: Halaba 2016, E-8: Melkasa 2017, E-9: Dhera 2017, E-10: Asasa 2017, E-11: Kulumsa 2017 and E-12: Haramaya 2016

\section{AMMI Model Analysis}

The grain yield data were subjected to AMMI analysis which combines ANOVA with additive and multiplicative parameters into a single model [20]. The combined ANOVA for grain yield showed that the three sources of variation namely environments, genotypes, and GEI were significant at $1 \%$ (Table 3). AMMI multiplicative component further partitioned the GE interaction into ten interaction principal component axes (IPCAs). However, only the first five axes showed a significant contribution to the GEI in the AMMI model at $1 \%$. The remaining five principal components contributed an insignificant portion of the variation. The first two IPCAs accounted for the largest proportion of $82.00 \%$ interaction sum of the square while the other nine IPCAs only accounted for $18.00 \%$, indicating the first two interaction principal components were sufficient to explain the interactions (Table 3). Many researchers witnessed that the best accurate AMMI model prediction can be made using the first two IPCA [13]. Therefore, the dataset obtained from the interaction of 15 genotypes tested at eight environments was best predicted by the first two IPCAs. Approximately as much variation in grain yield was explained by the interaction term captured by IPCA1 $(73.7 \%)$ as by the genotypic main effect. This showed that interaction is as important as the genotypic main effect, implying that both specific and wide adaptations are important. In the biplot axes system, either main effects and IPCA1, or IPCA1 and IPCA2 are commonly used as abscissa and ordinates [21].

AMMI-2 interaction biplots for grain yield of 15 bread wheat genotypes tested in 2016 and 2017 showed in Figure 1.
AMMI-2 biplot generated by using the first two interaction principal component axes (IPCA 1 and 2) used to the visual interpretation of the GEI patterns and identify genotypes or locations that exhibit low, medium, or high levels of interaction effects. Generally, most of the environment having longer vectors projected from the origin and it indicates the ability of the environment to discriminate the tested genotypes and they are providing good information (exert strong interaction effects) among genotypes. Thus, in this study E-3 (Asasa 2016), E-10 (Asasa 2017), E-11 (Kulumsa 2017) and E-1 (Kulumsa 2016) had long vectors and high IPCA scores, and indicating that these locations give good information (then contributed more interaction effects) among genotypes as compared to the other locations. Environments with short vectors also did not exert strong interaction effects while those environments that have long vectors located away from the origin exert strong interaction effects (maximum discriminating power). Thus, in this study E-12 (Haramaya 2016) and E-2 (Dhera 2016 had relatively short vectors by which they did not exert a strong interactive force (minimal discriminating power). Especially, E-12 (Haramaya 2016) had the shortest vector as compared to the rest environments and recorded above-average mean grain yield, therefore, it is the most ideal environment for the tested bread wheat genotypes. Similar results were reported by [22 23 and 24]. On the other hand, there are closer relationships between tested environments, E12 (Haramaya 2016) and E8 (Melkasa 2017) and E7 (Halaba 2016) and E6 (Alem Tena 2016) (Figure 1).

Genotypes with a smaller vector angle in between and 
have a similar projection, designate their proximity in the grain yield. Those genotypes that are clustered closer to the center are non-sensitive to environmental interactive forces and tend to be stable and those plotted far apart are sensitive and have large interactions and are unstable in yield. AMMI 2 biplot indicated that G6, G7, G4, G8, and G3 were located farthest from the origin of the biplot which indicated the most responsive (interactive) genotypes and most sensitive to the environment, contributed the highest interaction effects and G4, and G3 had high yield greater than overall mean yield while, G6, G7, and G8 had low yield which is less than overall mean yield. The genotypes occurring close together on the biplot origin will tend to have similar yield responses in all testing environments, while those located far apart may be indicated either differ in mean grain yield or show a different pattern of response over the environments. G9, G12, G2, G13, and G15 were close to the origin and hence insensitive to environmental change.

The genotype ETBW8260 (G4) exhibited high mean grain yield and well performed to the tested environments by which released with the local name "Balcha" won in environment Kulumsa 2016 (E-1) and Asasa 2016 (E-3) in 2016 and ETBW8261 (G5) won in Halaba 2016 (E-7), Asasa 2017 (E-10) and Kulumsa 2017 (E-11). Genotype ETBW8260 (G4) has a moderately resistant response to yellow rust disease with a low present of severity and ETBW8261 (G5) has moderately resistant and some moderately susceptible types of reaction. The current result is in agreement with [24 and 25] who reported the reaction of bread wheat genotypes to wheat rust diseases. Among the fifteen bread wheat genotypes tested across eight locations in two consecutive cropping seasons, genotype ETBW8260 (G4) was selected as early maturing, high yielding, resistant to yellow rust, and fitting for low to midland wheat-growing areas. Besides, this bread wheat variety has a yield advantage over the standard Ogolcho and the local Kakaba. So, this variety was officially released in 2019 by the name Balcha and recommended for low to midland wheat-growing agroecological zones in Ethiopia.

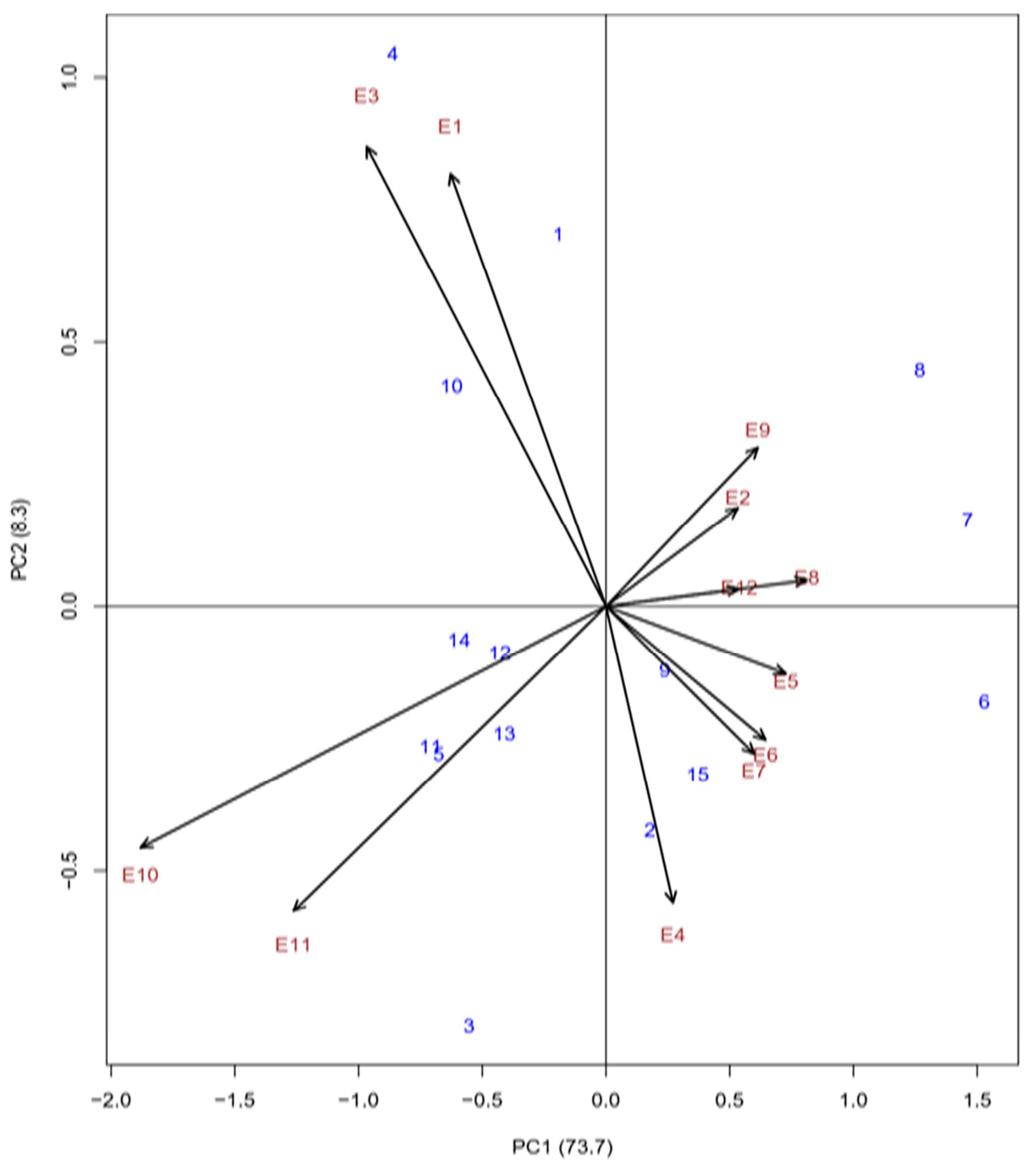

Figure 1. AMMI 2 Biplot of IPCA 1 against IPCA 2 for grain yield of 15 bread wheat genotypes.

Where; E1: Kulumsa 2016, E2: Dhera 2016, E3: Asasa 2016, E4: Melkasa 2016, E5: Arsi Nagele 2016, E6: Alem Tena 2016, E7: Halaba 2016, E8: Melkasa 2017, E9: Dhera 2017, E10: Asasa 2017, E11: Kulumsa 2017 and E12: Haramaya 2016 


\section{AMMI Stability Value}

The difference in stability measurement of the two principal components can be compensated by a proportional difference between the IPCAs (1:2) then determined by Pythagoras theorem in the effect of AMMI stability value. [26] noted that AMMI stability value (ASV) is not for quantitative stability measure rather quantify and rank genotypes according to their yield stability. The interaction principal component one (IPCA1) scores and the interaction principal component two (IPCA2) in the AMMI model are indicators of stability. The genotype with lower ASV values is considered more stable and genotypes with higher ASV are unstable. Accordingly, genotypes ETBW8303 (G2), Ogolcho (G1), ETBW8348 (G9), and Kakaba (G15) had to descend low ASV with ASV of $1.65,1.86,2.13$ and 3.32 respectively which indicating their low level of interaction with the environment and most stable genotypes among tested genotypes (Table 5). The genotype ETBW8076 (G6), ETBW8085 (G7), ETBW8289 (G8), and ETBW8260 (G4) were the most unstable genotypes with ASV value of 13.6, $13,11.3$, and 7.75 in grain yield respectively (Table 5)

\section{Yield stability index (YSI)}

Stability is not the only parameter for selection, because the most stable genotypes would not necessarily give the best yield performance [27] hence there is a need for approaches that incorporate both mean yield and stability in a single index, that is why various authors introduced different selection criteria for simultaneous selection of yield and stability: rank-sum, modified rank-sum, and the statistics yield stability [28 and 29]. In this regard, ASV takes into account both IPCA1 and IPCA2 and justifies most of the variation in the GEI. The least YSI is considered as the most stable with a high yield mean. It was applied to identify highyielding stable genotypes in cereal crops like durum wheat [26] and maize [30]. By using these measures, the suitable wheat genotype can be identified for varying existing environmental conditions. Based on YSI, the most stable genotype with high grain yield is genotype Ogolcho (\#15) with the value of YSI 9 followed by ETBW8303 (G2), ETBW8454 (G12), ETBW8261 (G5), ETBW8406 (G10), ETBW8310 (G3) and ETBW8260 (G4) with the value of YSI $10,10,12,12,13$ and 13 respectively (Table 5).

The present results indicated that linear regression for the average grain yield of a single genotype on the average yield of all varieties in each environment resulted in regression coefficients ( $b i$ values) ranging from 0.01 to 1.54 . This variation in regression coefficients indicates different responses of varieties to environmental changes (Table 5). The following varieties viz. Ogolcho has mean regression coefficient (bi) close to one; minimum values for deviation from regression, and higher grain yield than the grand mean indicting it is adapted well to all environments (wider adaptation over different environments. In contrast, varieties viz. ETBW8260, ETBW8406, ETBW8437, ETBW8261, ETBW8310, ETBW8394, ETBW8454 and ETBW8387 had regression coefficients greater than 1 , and they were regarded as sensitive to environmental changes; therefore, can be recommended for cultivation under favorable conditions (adapted well to good conditions). The varieties viz. ETBW8303, ETBW8348, Kakaba, ETBW8289, ETBW8085, ETBW8076 having the regression coefficient lower than 1 and lower grain yield than the grand mean except ETBW8303 and adapted badly to poor conditions (poorly adapted across environments and might have specific adaptation to unfavourable conditions). The most stable bread wheat genotype as indicated by Shukla and ecovalence stability parameter were ETBW8303, Ogolcho, Kakaba, ETBW8348, ETBW8387 and they had small contribution to GxE interaction. The bread wheat genotype with a poor stability according these procedure were ETBW8289, ETBW8085 and ETBW8076.

Table 5. Mean grain yield, univariate stability analysis of 15 bread wheat genotypes across different environments.

\begin{tabular}{|c|c|c|c|c|c|c|c|c|c|}
\hline Code & Genotype & GYLD & ASV & YSI & CV\% & bi & Sdi & Shukla & Wi \\
\hline G1 & Ogolcho & 3.59 & 1.86 & 9 & 41.45 & 1.09 & 0.12 & 0.2 & 2.51 \\
\hline $\mathrm{G} 2$ & ETBW8303 & 3.42 & 1.65 & 10 & 36.45 & 0.92 & 0.02 & 0.09 & 1.42 \\
\hline G4 & ETBW8260 & 4.18 & 7.75 & 13 & 50.79 & 1.54 & 0.46 & 1.11 & 11.15 \\
\hline G5 & ETBW8261 & 3.88 & 6.03 & 12 & 46.7 & 1.34 & 0.19 & 0.48 & 5.14 \\
\hline G6 & ETBW8076 & 2.29 & 13.6 & 29 & 34.46 & 0.01 & 0.57 & 2.53 & 24.7 \\
\hline G7 & ETBW8085 & 2.02 & 13 & 29 & 53.18 & 0.19 & 1.08 & 2.47 & 24.08 \\
\hline G8 & ETBW8289 & 2.77 & 11.3 & 26 & 32.8 & 0.3 & 0.63 & 1.65 & 16.34 \\
\hline G9 & ETBW8348 & 3.08 & 2.13 & 15 & 40.98 & 0.9 & 0.15 & 0.24 & 2.85 \\
\hline G10 & ETBW8406 & 3.83 & 5.58 & 12 & 49.81 & 1.44 & 0.06 & 0.49 & 5.29 \\
\hline G11 & ETBW8437 & 3.68 & 3.67 & 15 & 51.72 & 1.41 & 0.19 & 0.58 & 6.14 \\
\hline G12 & ETBW8454 & 3.74 & 3.82 & 10 & 44.51 & 1.22 & 0.19 & 0.35 & 3.9 \\
\hline G14 & ETBW8394 & 3.45 & 5.29 & 16 & 51.57 & 1.3 & 0.24 & 0.49 & 5.22 \\
\hline G15 & Kakaba & 3.14 & 3.32 & 15 & 35.81 & 0.8 & 0.1 & 0.24 & 2.82 \\
\hline
\end{tabular}




\section{Conclusion and Recommendations}

Plant improvement involves jointly the manipulation of genetic characteristics to optimize productivity in relation to the limitations of the environmental factors. Whenever varieties are proposed for commercial production, information on $\mathrm{G} \times \mathrm{E}$ interaction and stability-indicating their wide and/or specific adaptations needs to be available to the users. In varying environments it may be expected that the interaction of genotype by environment will also be varying and ample. As a result one cultivar may have the highest yield in one environment, while a second cultivar may excel in others. This necessitated the study of genotypes by environment interaction to estimate the magnitude of interactions in the selection of genotypes across several environments by calculating the average performance of the genotypes under evaluation. It is not recommended to develop and release a single genetic background of varieties across all locations, since Ethiopia is historically vulnerable to the rust epidemic due to mega variety deployment. However, there is a possibility to use a single variety across different wheat-growing agro-ecology of Ethiopia by designing systematic variety deployment strategy. This study demonstrated the importance of multi-location variety trials in Ethiopia to select the best genotypes adapted to a wide range of environments as well as to specific locations. The present study also revealed that bread wheat yield was liable to significant fluctuations with changes in the growing environments followed by the interaction and genotypic effect contributing the least. Significant genetic differences among genotypes for yield and yield components exhibited the existence of sufficient variability to have an effective selection. The genotype ETBW8260 and ETBW8261 are the best genotypes identified and verified along with standard checks and local check-in 2018 as variety verification trials in multi-location trials across the testing environments with superior in grain yield performance, yield stability, and wide adaptation. They have a better agronomic performance with resistance to rust disease compared to the standard checks. Finally, cultivation of the new variety is recommended in major wheat-growing regions (low to midland) of the country having similar agro-ecologies with the testing environments. This finding could be useful for plant breeders in performance trials by targeting appropriate bread wheat genotypes to various environments and by identifying the best environment to economical limitations such as time and cost resources. In general, among the fifteen bread wheat genotypes tested across eight locations in two cropping seasons, genotype ETBW8260 was selected as early maturing, high yielding, resistant to rust, and fitting for lowland to midland wheat-growing areas. So, this variety was officially released in 2019 by the name Balcha and recommended for lowland to midland agro-ecological zones

\section{Acknowledgements}

The author would like to thank staff members of the National wheat research department who managed the field experiment. The authors also would like to acknowledge the financial support provided by the Ethiopian Institute of Agricultural Research and Kulumsa Agricultural Research Center.

\section{References}

[1] Harlan JR. 1971. Agricultural origins: Centers and Noncenters. Science 174 (4008): 468-473.

[2] Demeke, M., \& Marcantonio, D. 2013. Analysis of incentives and disincentives for wheat in Ethiopia. Technical notes series. MAFAP, FAO.

[3] Bergh, K., Chew, A., Gugerty, M. K., \& Anderson, C. L. 2012 Wheat value chain: Ethiopia (Evince School Policy Analysis and Research, EPAR Brief number 104). Univerity of Washington.

[4] Nigussie, A., Kedir, A., Adisu, A., Belay, G., Gebrie, D., \& Desalegn, K. 2015. Bread wheat production in small scale irrigation users agro-pastoral households in Ethiopia: Case of Afar and Oromia regional state. Journal of Development and Agricultural Economics, 7 (4), 123-130.

[5] Central Statistical Agency (CSA). 2018. Agricultural sample survey 2017/18 (2010 E. C.) Volume 1. Report on area and production of major crops (Private peasant holdings, Mehere season). Statistical Bulletin 586. Addis Ababa, Ethiopia.

[6] Moldovan, V., Moldovan M., and Kadar R. 2000. Item from Romania. S. C. A. Agricultural Research Station. Turda, 3350, str. Agriculturii 27 Jud Chuj, Romania.

[7] Annicchiarico, P., 2002. Genotype x environment interactions: challenges and opportunities for plant breeding and cultivar recommendations (No. 174). Food \& Agriculture Org.

[8] Ashraf, M., Ahmad, A. and Mc Neilly, T., 2001. Growth and photosynthetic characteristics in pearl millet under water stress and different potassium supply. Photosynthetica, 39 (3), pp. 389-394.

[9] Ayalneh, T., Letta, T. and Abinasa, M., 2014. Assessment of Stability, Adaptability and Yield Performance of Bread Wheat (Tritium Aestivum L.) Cultivars in South Estern Ethiopia. Plant Breeding and Seed Science, 67 (1), pp. 3-11.

[10] Dawit. A. Tigabu, Zerihun Tadesse, Habtemariam Zegeye and Alemayehu Assefa. 2017. Seasonal variability and genetic response of elite bread wheat lines in drought prone environments of Ethiopia. J. Plant Breed. Genet. 05 (01). 1521.

[11] Gadisa A. Wardofa, Hussein M, Dawit A, and Tesfahun A. 2019. Genotype $\mathrm{x}$ environment interaction and yield stability of bread wheat genotypes in Central Ethiopia. Journal of Plant Breeding and Genetics, 7 (2), pp. 87-94.

[12] Mohammad. F., O. S. Abdalla, S. Rajaram, A. Yaljarouka, N. U. Khan, A. Z. Khan, S. K. Khalil, I. H. Khalil, I. Ahmad and S. A. Jadoon. 2011. Additive main effect and multiplicative analysis of synthetic-derived wheat under varying moisture regimes. Pak. J. Bot. 43 (2): 1205-1210.

[13] Yan, W., L. A. Hunt, O. Sheng and Z. Szlavnics 2000. Cultivar evaluation and mega environment investigation based on the GGE biplot. Crop Sci., 40: 597-605. 
[14] Crossa, J. 1990. Statistical analysis of multi-location trials. Advances in Agronomy, 44: 55- 85.

[15] Purchase, J. L., H. Hatting and Cs. Van de venter. 2000. Genotype by environments interaction of wheat in South Africa: stability analysis of yield performance. South Africa Journal of plant science 17: 101-107.

[16] Mohamed, N. E. and A. A. Ahmed. 2013. Additive main effects and multiplicative interaction and GGE biplot analysis of genotype $x$ environment interactions for grain yield in bread wheat (Tritium aestivum L.). African Journal of Agricultural Research, 8: 5197-203.

[17] Temesgen, M., S. Alamerew and F. Eticha. 2015. GGE Biplot Analysis of Genotype by Environment Interaction and Grain Yield Stability of Bread Wheat Genotypes in South East Ethiopia. World Journal of Agricultural Sciences, 11: 183-90.

[18] Heidari, S., Azizinezhad, R. and Haghparast, R., 2017. Determination of Yield Stability in Durum Wheat Genotypes under Rainfed and Supplementary Irrigation Conditions. Journal of Agricultural Science and Technology, 19 (6), pp. $1355-1368$.

[19] Kang, M. S. and Pham, H. N., 1991. Simultaneous selection for high yielding and stable crop genotypes. Agronomy journal, 83 (1), pp. 161-165.

[20] Gauch Jr, H. G., 1988. Model selection and validation for yield trials with interaction. Biometrics, pp. 705-715.

[21] Zobel, R. W., Wright, M. J., \& Gauch, H. G. 1988. Statistical analysis of a yield trial. Agronomy Journal, 80 (3), 388-393.

[22] Golkari, S., Hagparast, R., Roohi, E., Mobasser, S., Ahmadi, M. M., Soleimani, K., Khalilzadeh, G., Abedi-Asl, G., \& Babaei, T. 2016. Multi-environment evaluation of winter bread wheat genotypes under rainfed conditions of Iran-using AMMI model. Crop Breeding Journal, 4 (6), 17-31.
[23] Neisse, A. C., Kirch, J. L., \& Hongyu, K. 2018. AMMI and GGE Biplot for genotype $\times$ environment interaction: a medoid-based hierarchical cluster analysis approach for highdimensional data. Biometrical Letters, 55 (2), 97-121.

[24] Agegnehu Mekonnen, Firew Mekbib and Arega Gashaw. 2019. AMMI and GGE biplot analysis of grain yield of bread wheat (Tritium aestivum L.) genotypes at moisture deficit environment of Wollo, Ethiopia. Journal of Agricultural Science and Practice Volume 4 (1), pp. 9-19, https://doi.org/10.31248/JASP2019.123.

[25] Tamene, M., Tesfaye, L., Tilahun, B., Mohamed, A., Ayalneh, T., Bekele, H., Wubishet, A., Mulatu, A. 2018. Bread Wheat Varietal Development and Release in Southeastern Highlands of Ethiopia. American Journal of Biological and Environmental Statistics, 4 (1), 15-19.

[26] Purchase, J. L. 1997. Parametric analysis to describe genotype $\mathrm{x}$ environment interaction and yield stability in winter wheat, University of Free State. Bloemfontein, South Africa.

[27] Mohammadi, R., M. Roostaei, Y. Ansari, M. Aghaee and A. Amri. 2010. Relationships of phenotypic stability measures for genotypes of three cereal crops. Canadian Journal of Plant Science, 90: 819-30. https://doi.org/10.4141/cjps09102

[28] Farshadfar, E. 2008. Incorporation of AMMI Stability Value and Grain Yield in a Single NonParametric Index (GSI) in Bread Wheat. Pakistan Journal of Biological Sciences, 11: 1791-96. https://doi.org/10.3923/pjbs.2008.1791.1796

[29] Atta, B. M., T. M. Shah, G. Abbas and M. A. Haq. 2009. Genotype x environment interaction for seed yield in kabuli chickpea (Cicer arietinum L.) genotypes developed through mutation breeding. Pakistan Journal of Botany, 41: 188390.

[30] Fan, X.-M., M. S. Kang, H. Chen, Y. Zhang, J. Tan and C. Xu. 2007. Yield Stability of Maize Hybrids Evaluated in MultiEnvironment Trials in Yunnan, China. Agronomy Journal, 99: 220. https://doi.org/10.2134/agronj2006.0144 